\title{
A Escrita de Cartas em Psicoterapia de Grupo
}

\author{
Ludoana Pousa Corrêa de Paiva \\ Emerson F. Rasera* \\ Universidade Federal de Uberlândia, Uberlândia, Minas Gerais, Brasil
}

\begin{abstract}
RESUMO
Esse estudo investigou o uso de conceitos e práticas terapêuticas construcionistas sociais na escrita de cartas em sessões de psicoterapia de grupo. Ele se baseou, especificamente, na ilustração dos procedimentos propostos por Chen para a redação das cartas. Para tanto, foram realizadas 12 sessões grupais, com dez participantes, e utilizadas cartas terapêuticas. Observamos que os procedimentos de linguagem propostos são úteis para a construção de novas narrativas, bem como identificamos a necessidade de procedimentos que visem fortalecer o senso de grupalidade. Concluímos que os procedimentos utilizados oferecem transparência e visibilidade ao modo de redação da carta, além de servirem como um orientador para os interessados em escrever cartas terapêuticas.
\end{abstract}

Palavras-chave: comunicação escrita; psicoterapia de grupo; processo grupal; construcionismo social.

\begin{abstract}
The Writing of Letters in Group Psychotherapy

This study investigated the use of social constructionist concepts and therapeutic practices on the writing of letters in group psychotherapy. It aimed, particularly, to illustrate the use of the procedures proposed by Chen to the writing of letters. 12 group sessions with 10 patients were carried out and therapeutic letters were written. We observed that the proposed language procedures are useful for the construction of new narratives and identified the need for procedures to strengthen the sense of membership in the group. We concluded that those procedures provide transparency and visibility of the specifics of the letter writing, as well as serve as a guide for those interested in writing therapeutic letters.
\end{abstract}

Keywords: written communication; group psychotherapy; group process; social constructionism.

As ideias construcionistas têm sido utilizadas e vêm se concretizando, no campo da psicoterapia, por meio de propostas de intervenção baseadas em uma nova descrição da postura do terapeuta e do processo terapêutico (Andersen, 1999; Anderson \& Goolishian, 1998; Rasera \& Japur, 2007; White \& Epston, 1990). Dentre outros aspectos, podemos destacar nessa abordagem psicoterápica uma postura de co-construção entre terapeuta e cliente, $\mathrm{o}$ foco nos relacionamentos e em como esses são construídos e significados entre as pessoas, a ênfase nos processos linguísticos e, consequentemente, nas múltiplas formas de se descrever um problema.

A terapia narrativa é uma dessas propostas influentes no campo do construcionismo social. Ela se baseia no conceito de narrativa como uma "organização por meio do discurso, por meio de termos, símbolos ou metáforas, de um fluxo da experiência vivida, em uma sequência temporal e significativa" (Grandesso, 2000, p. 199). O terapeuta narrativo investiga as histórias construídas pelas pessoas, buscando reeditá-las e ressignificá-las, a partir da construção de novas histórias. Sustentado em uma epistemologia pós-moderna, esse processo de desconstrução e reconstrução de sentidos é realizado em colaboração com o cliente, destacando as narrativas subjugadas em detrimento das narrativas dominantes, o que lhe possibilita criar novos recursos de ação.

É nesse contexto que o termo "cartas terapêuticas" é criado e desenvolvido por White e Epston (1990), denominando as cartas escritas pelo terapeuta e direcionadas aos pacientes. Contudo, as cartas terapêuti-

* Endereço para correspondência: Emerson F. Rasera - emersonrasera@gmail.com 
cas, tal como presentes na literatura, foram enriquecidas com as contribuições de outras propostas construcionistas em terapia, e não utilizam recursos empregados apenas na terapia narrativa, mas também aqueles da abordagem colaborativa de Harlene Anderson (Anderson \& Goolishian, 1998) e dos processos reflexivos de Tom Andersen (Andersen, 1999).

Atualmente, o uso da escrita na clínica tem sido crescente por meio de variados documentos utilizados na prática diária do profissional de saúde, tais como os relatórios avaliativos, os registros de casos clínicos em prontuários e as cartas de encaminhamento feitas para outros profissionais (Pierides, 1999; Pyle, 2004, 2009; Oliver, Nelson, Cade, \& Cueva, 2007; Thomas, 1998). Tais formas de escrita são realizadas frequentemente pelo terapeuta, relatando impressões sobre o cliente, e são tidas, geralmente, como uma escrita administrativa, atendendo a normatizações que estabelecem a manutenção do registro escrito das sessões, que comumente ficam em sigilo entre os profissionais e as instituições.

Alguns terapeutas reconhecem na escrita vantagens adicionais, apontando que essa pode ser útil para atuar como outra forma de se comunicar com seus clientes, bem como um recurso para que eles se expressem (Augusta-Scott, 2007; Bell, Moules, \& Wright, 2009; Madigan, 2007; Moules, 2009a, 2009b). A partir da percepção dessas vantagens, desenvolvem-se diferentes maneiras de utilizar a linguagem escrita na clínica, dentre as quais podemos destacar o uso de cartas, em que: 1) o paciente escreve cartas (para si, para outras pessoas ou para determinado objeto); 2) o terapeuta e paciente escrevem entre si e 3) o terapeuta escreve cartas para o paciente.

Chen, Noosbond e Bruce (1998) afirmam que psicólogos clínicos despendem um tempo valioso anotando as histórias das consultas em prontuários e, se assim o fazem, por que não tornar esse instrumento uma ferramenta efetiva de intervenção? Além do que, se a busca é por uma relação igualitária entre terapeuta e cliente, em um processo de co-construção, nada mais coerente do que a história do cliente na terapia ser escrita em conjunto, em um processo de negociação, desmistificando o que antes era desconhecido por ele.

As autoras apontam ainda alguns benefícios das cartas terapêuticas tanto para os clientes quanto para os terapeutas. Em relação aos clientes, elas apontam que: a) ler o documento terapêutico entre as sessões permite que os clientes se distanciem para reflexão, além do imediatismo e intensidade da sessão; b) a nova linguagem de mudança também é útil como modelo, para que os clientes a internalizem em suas futuras autonarrações; c) como o documento terapêutico acentua as competências dos clientes, mudanças amplas se tornam possíveis. Em relação aos benefícios para os terapeutas, as autoras citam: a) a transparência dos terapeutas com os clientes é aumentada; b) oferece aos terapeutas tempo para ponderar acerca dos processos fora das interações do aqui - agora da sessão; c) uma vez aprendido, o documento terapêutico pode ser facilmente implementado.

Vários estudos têm sido conduzidos e publicados, enfatizando os benefícios que o atendimento com cartas pode promover (Erlingsson, 2009; Kress, Hoffman \& Thomas, 2008). Entretanto, essas pesquisas se concentram no campo de cartas que são escritas pelos pacientes, sendo amplamente utilizadas em contextos individuais, familiares e grupais. No que se refere às cartas escritas por terapeutas para pacientes, as pesquisas ainda são em pequeno número, mas apontam um interesse para a área, ganhando destaque nos últimos dez anos (Vidgen \& Williams, 2001). Dentre os artigos relacionados às cartas terapêuticas, identificados por uma busca combinada no Psychinfo, no período até 2011, com os descritores "psychotherapy" and "written communication", encontramos apenas um que voltou seu foco de investigação para a escrita no contexto grupal (Chen, Noosbond \& Bruce, 1998), corroborando para o entendimento desse trabalho como uma prática inovadora.

Em seu modelo, Chen et al. (1998) desenvolvem quatro princípios e treze procedimentos possíveis de serem utilizados na redação das cartas terapêuticas, quais sejam, I) desconstrução do self subjugado: 1) externalização, 2) personificação e 3) contextualização do problema; II) a busca por exceções: 4) identificação de acontecimentos extraordinários e 5) promoção de uma linguagem de transição; III) manter uma postura de não saber: 6) substituição de suposições por curiosidade, 7) imaginando possibilidades e 8) convidando os membros à reflexividade; e IV) a internalização do agenciamento pessoal: 9) atribuindo intencionalidade positiva, 10) legitimando sentimentos, 11) colocando os membros como agentes ativos, 12) creditando influência ambiental e 13) pontuando competências. 
Assim, considerando a importância das cartas na prática clínica, como possibilidade de intervenção terapêutica e documentação nesse contexto, bem como a escassez da literatura na área internacional, percebemos como necessária a realização de mais estudos nesse campo, buscando gerar novas conversações e entendimentos em relação ao tema. Baseado em tal propósito, esse estudo teve como objetivo investigar o uso de conceitos e práticas terapêuticas construcionistas sociais na escrita de cartas em sessões de psicoterapia de grupo. Ele se baseia, especificamente, na ilustração do uso dos princípios e procedimentos propostos por Chen et al. (1998), na redação de cartas, permitindo verificar sua utilidade e viabilidade no cotidiano profissional.

\section{MÉTODO}

\section{Contexto de construção do corpus}

O presente trabalho foi realizado a partir das cartas escritas a um grupo de curto prazo, com doze sessões de uma hora e meia de duração, que contou com a participação de dez pessoas, com idades e dilemas distintos referentes a dificuldades nas relações interpessoais, em uma Clínica-escola de Psicologia. Trata-se de uma modalidade regular de atendimento terapêutico que visa acolher a demanda do serviço.

Nesse sentido, o grupo estudado não contou com nenhuma forma especial de recrutamento, consistindo num exemplo comum de atendimento realizado na Clínica-escola. A composição grupal, seguindo as ideias construcionistas sociais (Rasera \& Japur, 2007), não se deu a partir de diagnósticos médicos, mas do interesse e disponibilidade dos participantes a se comprometerem com o processo grupal.

O modelo de atendimento teve como base as ideias construcionistas sociais, influenciada pelas contribuições da abordagem colaborativa, dos processos reflexivos e da terapia narrativa. Este modelo apresenta as seguintes características: o grupo é considerado uma prática discursiva; o terapeuta atua como facilitador do diálogo; a composição grupal é um processo negociado; o problema e a mudança são construídos na linguagem; e a saída do grupo é entendida como um rito de passagem (Rasera et al., 2006; Rasera \& Japur, 2007).

Além disso, o grupo contou com a presença de uma equipe reflexiva (Andersen, 1999), no qual, além da presença de uma terapeuta de campo para mediar as conversas grupais, havia duas outras terapeutas, que mantiveram uma posição de escuta, compartilhando suas reflexões no momento em que eram solicitadas pela terapeuta.

Todos os cuidados éticos necessários para a condução do estudo foram tomados e o projeto de pesquisa foi aprovado pelo Comitê de Ética em Pesquisa da universidade no qual ele foi desenvolvido.

\section{Construção e análise do corpus}

A redação das cartas foi inspirada pelas contribuições construcionistas sociais, incluindo conceitos e práticas colaborativas, narrativas e reflexivas (Andersen, 1999; Anderson \& Goolishian, 1998; Chen et al., 1998; White \& Epston, 1990). Elas foram redigidas pela terapeuta ao término de cada sessão e entregues e lidas por ela no início da sessão subsequente.

Após a leitura da carta na sessão, essa era submetida à aprovação por todos os presentes. Tipicamente, a carta era aceita por todos, com pequenas sugestões de esclarecimento ou mudança. Por isso, as cartas cumprem um papel ético de grande valia para os procedimentos terapêuticos ao compartilhar com cada participante os registros e criar espaço para sua alteração. Nesse sentido, é importante notar que a carta não tem como objetivo produzir uma descrição objetiva do que aconteceu na sessão. Mais do que isso, a carta tem um caráter fundamentalmente interventivo, buscando ser um instrumento que promova a mudança terapêutica. Apenas de forma secundária, mas não menos relevante, as cartas também foram utilizadas como documento de sessão, registrando o atendimento e cumprindo fins institucionais.

Norteada pelos princípios qualitativos e construcionistas de pesquisa (Guanaes \& Japur, 2008; McNamee, 2010), a análise se sustentou a partir de duas ideias. A primeira baseia-se no entendimento de que a carta se estrutura a partir de determinados objetivos terapêuticos. Nesse sentido, utilizamos para a análise os princípios e procedimentos desenvolvidos por Chen et al. (1998). A justificativa para o uso do modelo proposto por essas autoras nesta pesquisa deve-se a este ser um modelo apoiado em princípios de linguagem, por mesclar várias abordagens construcionistas e por ser um modelo voltado para o contexto grupal. Esses três fatores eram plenamente compatíveis com o modelo de grupo desenvolvido na Clínica-escola, o que torna- 
va a proposta de Chen et al. (1998) um complemento teoricamente sensível e empiricamente adequado. É importante destacar a contribuição desse modelo no campo da terapia construcionista em geral, e da terapia narrativa em particular, pois, para além do que White e Epston (1990) propõem, ele oferece diretrizes específicas para a prática psicoterápica grupal.

A segunda ideia orientadora da análise foca a linguagem como construtora da realidade, sendo entendida como ação no mundo (Gergen, 1996). A partir dessa noção, buscamos identificar as estratégias textuais de produção de sentido, ou seja, os diferentes recursos linguísticos utilizados na redação para alcançar os objetivos terapêuticos. Essa ideia parte da concepção que há uma diferença entre a proposição teórica e sua utilização nos contextos cotidianos, marcados por seu dinamismo e suas especificidades locais. A análise realizada permitiu ilustrar as formas que a terapeuta utilizou para dar sentido aos princípios e procedimentos propostos por Chen et al. (1998).

A análise da carta foi realizada pela terapeuta coordenadora do grupo e pelo seu orientador. O exercício de análise permitiu um aumento da reflexividade da coordenadora e a identificação das suas formas criativas, espontâneas, e sensíveis ao contexto de redigir as cartas. Reconhece-se, assim, a indissociação entre o contex to e o corpus construído. $\mathrm{O}$ diálogo com o orientador permitiu a explicitação e sistematização do seu modo de trabalho terapêutico, fazendo do cotidiano da clínica um espaço de produção de conhecimento.

\section{A construção das cartas}

Ao longo do atendimento, foram redigidas 12 cartas, as quais foram analisadas nesse estudo. A análise inicial das cartas mostrou que havia um padrão organizador das mesmas. De forma geral, o conteúdo das cartas voltou-se para o grupo, existindo parágrafos que se referiram às pessoas de forma individual, e parágrafos que englobaram o grupo como um todo. Cada um dos parágrafos apresentava um objetivo terapêutico. $\mathrm{O}$ foco da escrita da carta foi na linguagem utilizada e em como esta linguagem constrói mundos. Assim, um parágrafo escrito para alguém podia ecoar em questões de outro participante. Além disso, as cartas continham o nome da terapeuta, número da sessão e data.
Para a escrita das cartas, foram utilizadas apenas a inicial do primeiro nome de cada participante, o que possibilitou que todos os participantes se identificassem, reconhecessem os comentários e reflexões a eles dirigidos e obtivessem os resultados terapêuticos pretendidos, ao mesmo tempo, em que ficaram protegidos de leitores indevidos, especialmente, entre aqueles participantes que levavam as cartas para casa.

Considerando esse padrão orientador, e evitando análises repetitivas, escolhemos uma das cartas para ser investigada de forma aprofundada em relação aos seus princípios e procedimentos. A escolha dessa carta foi decorrente do fato dela ilustrar três dos quatro princípios apresentados por Chen et al. (1998), sendo representativa do modelo apresentado, bem como introduzir inovações identificadas nesse estudo.

Respeitando os limites de espaço para a redação desse artigo, apresentaremos a análise de sete parágrafos da carta e seus objetivos. O foco da análise encontra-se no processo de escrita da carta, a partir dos princípios e procedimentos utilizados para sua construção. Para esse fim, apresentaremos inicialmente os parágrafos da carta, sua identificação conforme os princípios descritos por Chen et al. (1998) e então analisaremos os recursos linguísticos utilizados. Os parágrafos da carta apresentados e analisados a seguir o foram de forma sequencial, respeitando sua ordem na carta analisada.

\section{Fortalecendo a grupalidade: o parágrafo inicial}

\section{Queridos membros do grupo,}

Antônio iniciou a sessão nos dizendo que sentiu que estamos conseguindo nos expressar um pouco melhor como grupo, e que os sentimentos estão ficando mais claros. Segundo ele, muitas vezes maquiamos os problemas por um tempo, mas, a partir da convivência com o grupo, ele conseguiu mostrar seus problemas sem essa maquiagem. Essa foi uma fala muito importante para mim dentro do grupo: ele nos contou que confiou a nós suas histórias. Fiquei curiosa em saber como vocês ouviram essa fala de Antônio e em como vocês estão se sentindo como grupo.

Gergen (1996) aponta que as palavras são uma forma de prática social, decorrentes das interações humanas. Sendo assim, é importante pensarmos em quais relações estamos construindo e/ou deixando de construir quando chamamos alguém de uma forma e não de outra. Nomear coisas, pessoas, grupos é criar 
identidades, jeitos de perceber, de se sentir pertencente ou não, querido ou não, cuidado ou não. Nesse contexto, o vocativo usado, "Queridos membros do grupo", chama a atenção em dois aspectos: o efeito do uso do adjetivo 'queridos' e a nomeação das pessoas presentes na sessão como 'membros do grupo'. O primeiro aspecto refere-se ao modo de a terapeuta se referir às pessoas que estão participando do processo terapêutico como "queridos". Esse qualificador a coloca como pessoa próxima e disposta a manter uma relação de afetividade com as pessoas que participam do grupo. Essa expressão também funciona como uma forma da terapeuta se apresentar com uma postura menos hierárquica e de maior proximidade com os clientes. Há certo tom coloquial e intimista/familiar nessa expressão que borra a distância técnica e profissional constitutiva do contexto de atenção em saúde. Pode-se entender que, por meio do uso dessa expressão, busca-se criar um contexto de intimidade e aproximação entre todos os envolvidos. Segundo Grandesso (2000), no contexto terapêutico é importante que o cliente fique à vontade para se abrir, para que ocorra diálogo, o que "requer a existência de um clima de confiança e aceitação para que os clientes possam se sentir ouvidos, confirmados, validados, compreendidos em seus sentimentos e pontos de vista" (p. 284). Nesse sentido, reforça-se o senso da terapia como uma prática colaborativa (Anderson \& Goolishian, 1998), pautada em atitudes de respeito, curiosidade e abertura.

Outro aspecto a ser observado é que todos os participantes são chamados como "membros do grupo", apontando assim para a construção de uma categoria, sem privilegiar um participante em especial. Nesse movimento, são realizados outros dois processos: 1) constitui esse grupo de pessoas como membros de um agrupamento específico, e 2) aponta que o trabalho realizado terá como foco o grupo. Assim, introduz-se a questão da grupalidade, buscando a formação do senso de identidade desses participantes o que, consequentemente, evoca sua corresponsabilização pelo processo de conversação e mudança.

No primeiro parágrafo da carta, a terapeuta ressalta que "Antonio iniciou a sessão", localizando os membros do grupo no ponto inicial da sessão anterior e oferecendo um relato cronológico. A sensação ao ler o primeiro parágrafo é a da construção de uma narrativa, nas quais temos a presença de um início, um meio e um fim. Os leitores adquirem, assim, uma familiaridade com o enredo que está por vir, um possível reco- nhecimento a partir da memória dos fatos, ao mesmo tempo em que é suscitada a curiosidade dos recortes que serão feitos pela terapeuta. Segundo White e Epston (1990), tal estruturação narrativa oferece às pessoas continuidade e significado em suas vidas, possibilitando que elas se apoiem nesse formato tanto para ordenar a continuidade da narrativa, quanto para interpretar as experiências posteriores.

No momento seguinte, a terapeuta comenta sobre como Antonio percebia o grupo e como ele o percebe agora. Esse recorte possibilita a utilização de outra voz que não a da terapeuta, a voz do participante que está inserido no contexto e, por isso, ganha maior legitimidade, para destacar aos demais participantes o processo de desenvolvimento do grupo. Utilizando desse recurso, a voz da terapeuta não fica isolada. A avaliação e valorização do grupo ganha um sentido de objetividade à medida que é compartilhada pela terapeuta e pelo participante. A estrutura da conversação na qual uma pessoa fala enquanto outras escutam sua história, e quem escuta reflete na história de quem narra, maximiza a possibilidade que cada um servirá como testemunha ou audiência para os outros, e minimiza as chances de que as pessoas disputem ou contradigam as histórias dos outros.

$\mathrm{Na}$ análise da carta, observamos o quanto a terapeuta se inclui no grupo, o que pode ser exemplificado com a frase "estamos conseguindo nos expressar melhor como grupo". Esse trecho poderia ter sido escrito de outra maneira, como "vocês estão conseguindo se expressar melhor como grupo", o que contemplaria uma terapeuta que se considera separada do "grupo". Porém, foi ressaltado na carta que Antonio "nos" disse, o que a inclui como parte desse grupo e redimensiona a possibilidade do entendê-la como uma especialista. Tal formatação vai ao encontro das concepções desenvolvidas por Anderson e Goolishian (1998), na qual o terapeuta busca interpretar e compreender as colocações do cliente, em constante diálogo e sem se isentar do processo de investigação, à espera do momento certo para usar suas concepções teóricas acerca do que é dito. O terapeuta se coloca no sistema terapêutico em busca de "aprender a singularidade da verdade narrativa de cada cliente, as verdades coerentes em suas vidas estoriadas" (Anderson \& Goolishian, 1998, p. 40).

Estruturar a frase dessa forma gera duas implicações: 1) diminui o caráter pedagógico, crítico e corre- 
tor da avaliação apresentada, e 2) coloca a própria terapeuta como sendo avaliada, não restringindo a avaliação aos demais membros do grupo. Ao se incluir no processo com os demais membros, ela facilita a construção do senso de grupalidade, de sentirem-se juntos, deixando em segundo plano as diferenças entre eles. Ao mesmo tempo em que a fala de Antonio é legitimada, a conversa se volta para a compreensão de como as demais pessoas estão se sentindo em relação a esse mesmo assunto. A carta não funciona apenas como um relato do que aconteceu, mas traz questionamentos que colocam os leitores-pacientes no lugar de quem deve responder ao que foi apresentado, criando um contexto para o diálogo. O convite para esse diálogo é feito pela terapeuta a partir de um lugar de curiosidade: "fiquei curiosa". Tal expressão não exige dos clientes uma resposta correta e objetiva, nem supõe que eles já saibam algo. Ela é exploratória, quase uma reflexão compartilhada, que mostra interesse e convida ao diálogo. A curiosidade como postura terapêutica possibilita a construção de outras formas de relacionamento, de ação e interpretação. Nesse contexto, as possibilidades terapêuticas vão sendo coconstruídas com o cliente.

\section{Convite à reflexividade: conversando com Lucas}

Lucas, fiquei contente pelas contribuições que você deu ao grupo. Você nos trouxe o enfrentamento de um medo seu, e em como você conseguiu lidar com isso dividindo suas preocupações com sua esposa. E então me lembrei de você nos contar do seu lado que fica pensando sozinho nas preocupações. Pensando nessas duas coisas, isso me fez refletir: Como você se sentiu dividindo com sua esposa uma preocupação? Será que você poderia dividir outras preocupações com outras pessoas? Como seria isso? Como isso poderia ser de ajuda?

Nas falas de Lucas, trazidas durante a sessão, a terapeuta recorta o tema 'medo' e o conecta ao que estava sendo apresentado no parágrafo anterior, relativo a Antônio. Ao construir essa interligação dos fatos, explicita-se uma continuação na conversa do grupo, oferecendo sequencialidade à narrativa (White \& Epston, 1990), bem como se aponta a existência de conexão grupal.

Ao considerar a fala de Lucas como "contribuições" dadas ao grupo, ou seja, ações que ajudaram o grupo, explicita-se a responsabilidade dos membros uns com os outros ao decidirem compartilhar suas histórias. Ressaltar que ele "conseguiu lidar" com seus medos, foca o sucesso no enfrentamento e destaca sua capacidade e seus recursos. Com isso, fortalece-se o senso de agenciamento (White \& Epston, 1990) e minimiza-se uma possível dependência com o saber da terapeuta (Tomm, 1988). É destacado o modo como Lucas realizou essa tarefa: "dividindo suas preocupações”. O recurso é pontuado e se torna disponível para os demais membros do grupo que passam pela mesma situação.

Nesse parágrafo, duas situações são relacionadas: a de um Lucas que divide as preocupações com a esposa e a de um Lucas que "fica pensando sozinho nas preocupações". Expor duas situações tão distintas em um mesmo momento permite que elas sejam analisadas, confrontadas e concluídas de um ponto de vista mais complexo e dinâmico, além de ressaltar o movimento de progresso, desenvolvimento e mudança no ato de compartilhar. Esse jeito de escrever favorece o desenvolvimento de novos entendimentos: quando eu compartilho, eu resolvo, e quando eu penso sozinho, eu me preocupo. Além disso, Lucas não é definido como uma pessoa que se preocupa sozinho e, em alguns momentos, compartilha. Ele é visto como alguém que possui os dois lados, o que desconstrói uma possível rigidez em seu modo de se perceber, facilitando o seu processo de mudança.

A terapeuta inicia as perguntas a partir de uma colocação: "Pensando nessas duas coisas, isso me fez refletir", o que permite que Lucas se situe em quais situações irá se basear para responder as perguntas. Além disso, ao afirmar que estava "pensando nessas duas coisas", o que "a fez refletir", a terapeuta está organizando um espaço que é de reflexão, convidando Lucas, a partir das perguntas subsequentes, a estar com ela na investigação do que tem sido trazido por ele. Chen et al. (1998) consideram esse processo de reflexividade parte da postura de não-saber, na qual questionamentos e comentários refletem a sincera curiosidade da terapeuta e seu desejo em aprender um pouco mais a respeito da vida do cliente. Para essas autoras, o convite à reflexividade permite que o cliente considere as ações e significados que modelam suas experiências. O posicionamento da terapeuta nos remete ainda aos processos reflexivos de Andersen (1999), entendido como uma maneira de conversar associada à formulação de perguntas, no qual se faz necessário que a terapeuta apresente uma disponibilidade para estar com o outro, para estar junto, manten- 
do uma postura curiosa. Os questionamentos realizados não têm qualquer intenção conclusiva ou diagnóstica, mas se apresentam como ofertas a novos diálogos, na busca da criação de novos entendimentos que possibilitem outros arranjos narrativos, mais condizentes e favoráveis à vida do cliente.

Outra questão levantada pela terapeuta diz respeito à rede de pessoas com a qual Lucas pode contar. Referir-se a essa rede escrevendo "será que você poderia", promove novas possibilidades e espaços para Lucas. O norteador para as perguntas "será que", "como seria", "como poderia" é a curiosidade genuína, que incita o cliente a refletir acerca de questões que já poderiam ter sido entendidas como dadas, gerando aberturas para a conversa e possibilidade de ampliação de sentidos. A des-hierarquização da terapeuta e a suspensão das pré-concepções são fatores primordiais para o bom desenvolvimento desse jeito de conversar.

Pensar no "poderia" permite ainda que Lucas hipotetize formas de ação, colocando-o como corresponsável pela ampliação desse jeito de agir. Utilizando os verbos no condicional "Como seria isso?" e "Como isso poderia ser de ajuda?", a questão é inserida no campo das possibilidades. Refletir no "como se" permite que o cliente explore as diferentes opções possíveis, de maneira confortável. O que antes era narrado como sofrimento e impasse adquire opções futuras, possibilitando que Lucas se afaste do que está sendo entendido como dado no presente, e permitindo que ele experimente outros lugares, conheça e teste o novo. Dessa forma, criam-se condições para que o sujeito possa exercitar uma postura reflexiva em outras situações de sua vida. Ao imaginar "como seria isso" e "como isso poderia ser de ajuda" criam-se oportunidades para Lucas considerar possibilidades que vão além daquelas coconstruídas em suas relações cotidianas, podendo avaliar o impacto dos problemas em sua vida de outras perspectivas, ao mesmo tempo em que lhe proporciona um senso de controle, já que lhe permite traçar planos múltiplos e lidar com os obstáculos.

Dessa forma, as perguntas reflexivas têm a intenção de serem facilitadoras. São perguntas que respeitam a autonomia do cliente, convidam a imaginar novas alternativas, tendem a abrir espaço para que se considerem novas percepções, perspectivas, direções e opções. Facilitam uma reavaliação das implicações problemáticas das percepções e comportamentos atuais. Como consequência, os clientes geram novas ligações e novas solu- ções de seu próprio jeito e em seu próprio tempo. $\mathrm{Na}$ terapeuta, tais perguntas tendem a guiá-la para que se torne mais criativa nas perguntas formuladas.

\section{Investigando acontecimentos extraordinários: conversando com Renata}

Renata, você dividiu conosco alguns medos que já apareceram e que você conseguiu enfrentá-los chutando o "balde do medo". Achei essa uma história de superação, que só pode vir de uma mulher determinada e de coragem. Você disse que se não fizesse isso, ninguém faria por você. E agora, Renata, o que mais você gostaria de fazer por você? Como convidar aquela coragem e determinação para te ajudar nessas novas histórias e com os velhos baldes que te trouxeram à terapia?

A terapia, como atividade linguística, promove, por meio da conversação, um campo de possibilidades para a produção colaborativa entre terapeuta e cliente (Grandesso, 2000). Para isso, é necessário que esse espaço seja construído ativamente pelas pessoas em relação, na busca de novos significados. Destacar que Renata "dividiu" seus medos com o grupo é apontar sua responsabilidade na construção desse espaço, construindo com o grupo a valorização de um espaço terapêutico como um lugar de compartilhar. Ao "dividir" a narrativa, Renata a constrói ativamente, junto ao grupo, dando significados e sentidos condizentes ao contexto da fala. A terapeuta enfatiza e legitima o relato da cliente ao nomear a história como de "superação", o que promove força ao relato construído.

$\mathrm{Na}$ sequência, a narrativa destacada pela terapeuta diz respeito aos medos que já apareceram e que foram enfrentados, sendo "chutados". Os medos, situaçãoproblema apresentada pela cliente, foram enfrentados a partir de uma ação realizada, uma atitude de enfrentamento. Nesse momento, os recursos de Renata são destacados, e é oferecido a todo o grupo um possível jeito de lidar com os medos que surgem, enfrentando-os. O uso da expressão "balde do medo", explicitado na carta, gera maior reconhecimento no discurso por parte de quem fala, por ter sido uma expressão criada e utilizada por eles, além de promover proximidade aos demais leitores.

Descrever os medos como figuras que "apareceram" e que foram enfrentadas, sendo "chutados", é uma forma de escrever que promove a externalização do problema. Essa maneira de apresentar os medos minimiza seu potencial causador de temor, pois ele 
"aparece", é "enfrentado" e "chutado". A sequência das palavras destaca o problema, o enfrentamento e a resolução, fortalecendo o senso de agenciamento de Renata. O discurso construído é um discurso de enfrentamento, apresentado como uma história de sucesso: alguém que enfrenta 'baldes' de medo e os chuta. Renata não é vista como alguém que ora tem coragem e determinação, ora não tem. Ela é descrita como uma mulher de determinação e coragem. Por meio dessa descrição, se fortalece uma narrativa de enfrentamento.

Atuar sobre histórias dominantes requer da terapeuta a busca pelos recursos e potencialidades do cliente, que possibilitam que a história dominante seja revista, a partir da atribuição de novos sentidos ao relato. Isso é possível por meio da identificação de aspectos previamente ignorados da experiência vivida pelo cliente. Esses aspectos ignorados foram nomeados por White e Epston (1990) de "acontecimentos extraordinários", que são definidos como incluindo "toda a gama de sucessos, sentimentos, intenções, pensamentos, ações, etc., que tem uma localização histórica, presente ou futura, e que o relato dominante não pode incorporar" (p. 32).

Ao identificar os acontecimentos extraordinários, as pessoas são convidadas a atribuir significados a eles, comprometendo-se na existência dessa nova narrativa. White e Epston (1990) ainda salientam que a construção de tais relatos, fora dos relatos dominantes, "constituem uma fonte cheia de riqueza e fertilidade, para a geração, ou regeneração de relatos alternativos" (p. 32).

Ao destacar essa fala de Renata, na qual ela aponta uma situação de enfrentamento e vitória e que ainda não havia sido apresentada antes, a terapeuta interrompe a representação habitual desses relatos. Ela aponta o acontecimento extraordinário e o amplia, pontua suas competências, e busca gerar um maior agenciamento interpessoal, bem como, possibilitar que Renata se sinta capaz de intervir em sua vida e relações. Dessa forma, exceções são ressaltadas em narrativas desencorajadoras (Chen et al., 1998), e as possibilidades e recursos já utilizados com sucesso em outros momentos reaparecem e são utilizados na história atual. Nesse sentido, busca-se apontar para a paciente que existem momentos nos quais ela conseguiu vencer as dificuldades, o que oferece oportunidade de ressignificação da situação.
Nesse trecho da carta, as ações de Renata são pontuadas como pertencentes a uma mulher de determinação e coragem, e o uso dos adjetivos auxilia na construção do discurso de uma mulher guerreira. A narrativa ainda é ampliada por questões que a convidam a refletir sobre novas ações a partir desse novo entendimento de uma mulher competente e com recursos. As perguntas realizadas na sequência enriquecem a história alternativa em construção. O interesse é na força, nas habilidades especiais e nas aspirações de Renata, que constroem uma história alternativa.

A questão "O que mais você gostaria de fazer por você?" sugere que Renata possui recursos para a resolução de outros problemas. Essa fala é fortalecida pelo recorte da frase dita pela paciente, que se ela não fizer por si mais ninguém o fará, destacando sua próatividade em resolver questões que são necessárias, de defender seus interesses. Tal construção linguística busca a internalização do agenciamento pessoal, reforçando um senso de autoeficácia e construindo uma descrição de Renata com maior gestão de sua vida. A formulação dessas questões gera implicações: 1) convidam Renata a refletir sobre evoluções específicas de sua vida, identificar e falar de suas experiências, buscando soluções para elas; 2) o acontecimento extraordinário destacado vai ganhando credibilidade. Ele passa a ser a base para a conversação na qual Renata tem a oportunidade de identificar e desenvolver relatos, gerando novas conclusões e significados para sua identidade e história, em uma significativa reconstrução de sentidos.

A construção do parágrafo utiliza-se do recurso da temporalidade: os acontecimentos passados significados com sucesso por Renata são conectados com os dilemas presentes e possíveis desdobramentos futuros, em sequência, gerando sentido de continuidade. A primeira parte do parágrafo, apresentada como uma história de sucesso, se torna um marco referencial para construir futuros possíveis, e a sequência das perguntas contribui para a construção de uma narrativa progressiva, na qual os acontecimentos ocorrem em uma dimensão crescente e a narrativa é construída em direção à progressão dos objetivos do protagonista (Gergen, 1996).

"Como convidar aquela coragem e determinação para te ajudar nessas novas histórias e com os velhos baldes que te trouxeram à terapia?" ressalta que as novas histórias, contextos e desafios podem ser en- 
frentados novamente, a partir dos recursos que foram explicitados: coragem e determinação. $\mathrm{O}$ discurso de enfrentamento, construído na primeira parte do parágrafo, sustenta nesse momento os recursos para os novos desafios que Renata percebe. Tal questionamento convida a cliente a sair do discurso de déficit para buscar recursos e construir na conversação um discurso de soluções de problemas.

\section{Atribuindo intencionalidade positiva: conversando com Elisa}

Elisa, achei bonito você dividir conosco sua pressa em ir embora e a ansiedade que estava te acompanhando durante todo o grupo. Fiquei feliz por você ter vindo e ficado, mesmo tendo tantas coisas lá fora te esperando. Isso possibilitou que a gente pudesse sentir o seu compromisso com o grupo. Fiquei emocionada ao você nos contar que tem uma história de vitórias, "desde o ventre". Imaginando que a gente se encontre daqui a um tempo, para que você me conte sobre como essas histórias de hoje se desenrolaram, que coisas você esperaria me contar? Como você planeja terminar esse capítulo da sua história, Elisa? O que precisará acontecer para o que você imagina e deseja aconteça?

A internalização do agenciamento pessoal é um procedimento linguístico utilizado para auxiliar o cliente a modificar suas percepções acerca de si mesmo (Chen et al.1998). Dessa forma, atitudes e sentimentos vistos por eles como negativos são ressignificados e adquirem novos entendimentos. Esse jeito de conversar fica explicitado logo ao início do parágrafo, quando o termo "achei bonito" ressalta e legitima o tipo de participação que Elisa teve no grupo. Nesse momento, pensando nas várias possibilidades acerca do significado de um evento, percebe-se o movimento em legitimar o compromisso de Elisa, oferecendo outro olhar, positivo, em relação à história trazida. Um relato que poderia causar constrangimento ou culpa (estar ansiosa e com pressa de ir embora) gera um discurso de aceitação e reconhecimento. A descrição de Elisa com pressa e ansiosa não é investigada nesse parágrafo, optando-se por desenvolver uma descrição que amplia e legitima ações antes não percebidas. A narrativa de Elisa foi redimensionada pela terapeuta, em consonância com o que Gergen (1996) denomina de ação suplementar ${ }^{1}$, pela qual o relacionamento humano é o gerador de linguagem e de entendimento. As histórias que Elisa constrói não têm sentido em si mesmas, e dependem do sentido que o outro atribuiu a ela. Dessa forma, a terapeuta possibilita outros entendimentos, por meio de um convite, que poderá, ou não, ser aceito por Elisa.

É destacado ainda que a ansiedade "acompanha" Elisa. Essa frase contempla uma ansiedade que é separada da pessoa de Elisa, apontando para o processo de externalização do problema, sendo colocada como algo externo. Essa descrição tanto gera outras descrições (que não a de uma pessoa ansiosa), como oferece possibilidade de enfrentamento (por não ser algo que faz parte dela). O termo "desde o ventre", citado por Elisa na sessão e realçado na carta, enfatiza sua vida de lutas e conquistas mesmo antes de nascer. Tal enfoque pontua as competências da cliente, talvez antes negligenciadas, a partir da criação de um discurso pautado na temporalidade.

Após a participação de Elisa ser contextualizada de forma positiva, ela é convidada a imaginar possibilidades, refletindo sobre possíveis metas a serem alcançadas. Esse é um movimento que se volta para o futuro, possibilitando que ela visualize seus projetos e reconheça o ponto de chegada ao alcançá-los. Entretanto, tal ação também diz respeito ao futuro próximo: "O que precisará acontecer para que o que você imagina e deseja aconteça?", em um convite ao cuidado com algumas questões atuais para o alcance das metas futuras. A possibilidade de reflexão dos acontecimentos futuros permite que Elisa se veja frente aos seus recursos passados e sua história presente, podendo planejar seus passos baseada no desenrolar de sua própria história. Além disso, convidar Elisa para essa conversa busca gerar reflexões acerca de como ela pode aproveitar o grupo para pensar suas questões.

\section{Revendo o processo grupal: o parágrafo de encerramento}

Fiquei comovida com essa sessão e com as histórias que escutei de cada um de vocês. Mais uma vez percebi o grupo se empenhando em ajudar uns aos outros e buscando se ajudar, relatando com sinceridade os medos que os acompanham e os baldes a serem chutados. Essas falas foram mescladas com histórias de superação e conquistas. Isso me deu uma sensação de que juntos podemos construir novas histórias, enfrentar os medos e chutar novos baldes. Senti muito a falta de Rogério e Mariana. Fico na expectativa do nosso próximo encontro. (Nome Terapeuta $-10^{a}$ sessão - (data) 
O parágrafo final é uma oportunidade para que a terapeuta exponha seus sentimentos ("fiquei comovida com essa sessão e com as histórias que escutei de cada um de vocês"), apresente suas percepções ("percebi o grupo se empenhando em ajudar uns aos outros e buscando se ajudar"), legitime a participação dos integrantes do grupo ("relatando com sinceridade os medos que os acompanham e os baldes a serem chutados"), destaque recursos ("Essas falas foram mescladas com histórias de superação e conquistas"), compartilhe expectativas ("Isso me deu uma sensação de que juntos podemos construir novas histórias, enfrentar os medos e chutar novos baldes") e cite o nome das pessoas faltantes, em uma postura tanto cuidadosa quanto funcional para fins de registro ("Senti muito a falta de Rogério e Mariana"), fortalecendo a noção de que a carta é escrita para todo o grupo e registrando o entendimento de que são todos que formam esse lugar.

Além disso, como destacado por Freedman e Combs (1996), as cartas oferecem um resumo do encontro prévio, convidando as pessoas a entrarem novamente nas conversações iniciadas anteriormente. Esse último parágrafo aponta, de maneira resumida, os eventos que chamaram a atenção da terapeuta, promovendo uma rememoração dos acontecimentos e possibilitando que os membros do grupo reflitam novamente, agora em conversações alternativas. Ainda segundo tais autores, essas conversações possibilitam que os sentidos de si, bem como dos dilemas com os quais se está lutando possam mudar, gerando uma nova história.

Nesse parágrafo, temos evidenciada a postura coparticipativa da terapeuta, que ativamente contribui como editora das histórias apresentada pelos clientes, apresentando novas possibilidades de sentido, organizando e dando coerência aos relatos. Tal finalização oferece uma sensação de fechamento e significado às novas narrativas que emergem.

A ideia de que, ao trabalharem juntos como grupo, as realizações virão com maior facilidade, é desenvolvida na frase em que é colocado que "isso me deu uma sensação de que juntos podemos construir novas histórias, enfrentar os medos e chutar novos baldes". A interação ganha lugar de destaque na resolução dos problemas e o conhecimento de todos é valorizado, o que enfatiza o senso de grupalidade.

Ao apresentar que está na "expectativa para o próximo encontro", a terapeuta aponta para a continuida- de da conversa e antecipa o convite para a próxima sessão. A carta é finalizada com o nome da terapeuta, número de sessão e data em que ocorreu, atendendo aos registros institucionais e transformando algo burocrático em um documento com outros sentidos.

\section{CONSIDERAÇÕES FINAIS}

Nesse estudo, em razão de o uso das cartas se situar no contexto grupal, frequentemente o primeiro e/ou último parágrafo das cartas foram utilizados para construir e/ou reforçar a grupalidade entre os membros. Apesar de tal prática ser realizada durante as sessões, na linguagem escrita ela adquire força e legitimidade. A ação de rever o processo grupal englobando os recursos e a sabedoria dos clientes aponta como essa construção foi realizada no contexto do grupo. São parágrafos que sintetizam os acontecimentos da sessão recortados pela terapeuta, o que oferece um senso de evolução para os participantes. Destacamos as novas categorias utilizadas presentes nesses dois parágrafos por entendermos que o processo de construção do grupo, bem como, o de fechamento das sessões a partir do olhar da terapeuta são de grande importância para a construção do processo psicoterápico como um todo. Assim, consideramos essas duas categorias - fortalecendo a grupalidade e revendo o processo grupal - tão relevantes quanto às descritas por Chen et al. (1998) para as cartas escritas no contexto grupal.

Refletindo acerca das questões apresentadas, percebemos que a carta terapêutica atua como um convite a múltiplas possibilidades de narrativas. Essa pode ser considerada uma conversação generativa, conceito proposto por Gergen e Kaye (1992), na qual diferentes pontos da experiência são ressaltados, permitindo que venham a surgir múltiplas perspectivas, resultando na construção de novos significados. Assim, a partir de sua leitura, espera-se que sejam compartilhadas ideias que possam ser ponto de partida para novas conversações ou para a descoberta de novas descrições e entendimentos. A carta, portanto, amplia o diálogo terapeuta-cliente, favorecendo que o campo de significado permaneça aberto para novas significações preferíveis. Refletir a respeito de sua estrutura e conteúdo possibilita ampliar a visão de sua utilidade clínica, bem como investigarmos novas maneiras de utilização.

Interação Psicol., Curitiba, v. 19, n. 3, p. 307-317, set./dez. 2015 


\section{REFERÊNCIAS}

Andersen, T. (1999). Processos Reflexivos. Rio de Janeiro: Instituto NOOS / ITF.

Anderson, H., \& Goolishian, H. (1998). O cliente é o especialista: a abordagem terapêutica do não saber. In: Mcnamee, S. \& Gergen, K. (Org.). A terapia como construção social (pp. 34-49). Porto Alegre: Artes Médicas.

Augusta-Scott, T. (2007). Letters from prision: re-authoring identity with men who have perpetratted sexual violence. In: C. Brown \& T. Augusta-Scott (Org.), Narrative Therapy: making meaning, making lives (pp.251-268). London: Sage.

Bell, J. M., Moules, N. J., \& Wright, L. (2009). Therapeutic letters and the family nursing unit: a legacy of advanced nursing practice. Journal of Family Nursing, 15(1), 6-30.

Chen, M., Noosbond, J. P., \& Bruce, M. A. (1998). Therapeutic document in group counseling: an active change agent. Journal of Counseling \& Development, 76, 404411.

Erlingsson, C. (2009). Undergraduate nursing students writing therapeutic letters to families: an educational strategy. Journal of Family Nursing, 15(1), 83-101.

Fredman, J., \& Combs, G. (1996). Narrative therapy: the social construction of preferred realities. New York: W. W. Norton.

Gergen, K. J. (1996) Realidades y relaciones: aproximaciones a la construcción social. Espanha, Barcelona: Paidós.

Gergen, K. J., \& Kaye, J. (1992). Além da narrativa na negociação do sentido terapêutico. In: S. Mcnamee \& K. Gergen (Orgs.), A terapia como construção social (pp. 201-222). Porto Alegre: Artes Médicas.

Grandesso, M. (2000). Sobre a reconstrução do significado. São Paulo: Casa do Psicólogo.

Guanaes, C., \& Japur, M. (2008). Contribuições da poética social à pesquisa em psicoterapia de grupo. Estudos de Psicologia (Natal), 13, 117-124.

Kress, V. E., Hoffman, R., \& Thomas, A.M. (2008). Letters from the future: the use of therapeutic letter writing in counseling sexual abuse survivors. Journal of Creativity in Mental Health, 3(2), 105-118.

Madigan, S. (2007). Anticipating hope within written and naming domains of despair. In: C. Flaskas, I. McCarthy, \& J. Sheehan (Org.) Hope and despair in narrative and family therapy: adversity, forgiveness and reconciliation (pp. 174-183). Hove: Brunner-Routledge.
McNamee, S. (2010). Research as social construction: transformative inquiry. Saúde \& Transformação Social, $1,9-19$.

Moules, N. J. (2009a). Therapeutic letters in nursing: examining the character and influence of the written word in clinical work with families experiencing illness. Journal of Family Nursing, 15 (1), 31-49.

Moules, N. J. (2009b). The past and future of therapeutic letters: family suffering and healing words. Journal of Family Nursing, 15 (1), 102-111.

Oliver, M., Nelson, K. W., Cade, R., \& Cueva, C. (2007). Therapeutic letter writing from school counselors to students, parents and teachers. The Professional School Counseling Journal, 10, 510-515.

Pierides, M. (1999). Writing to patients. Psychiatric Bulletin, 23, 385-386.

Pyle, N. R. (2004). Letters about letters: client's written reflections on therapeutic letters. Dissertação de Mestrado, Faculdade de Educação, Memorial University of Newfoundland, Canadá.

Pyle, N. R. (2009). Therapeutic letters as relationally responsive practice. Journal of Family Nursing, 15(1), 65-82.

Rasera, E. F., \& Japur, M. (2007). Grupo como construção social. São Paulo: Vetor.

Rasera, E. F., Santos, L. A., Faria, L. G. S., Aguiar, R. L. C., \& Pires, V. S. (2006). A construção de um estágio em psicoterapia de grupo: uma perspectiva construcionista social. Revista da SPAGESP, 7(2), 30-39.

Thomas, P. (1998). Writing letters to patients. Psychiatric Bulletin, 22, 542-545.

Tomm, K. (1988). Interventive interviewing - part III: intending to ask lineal, circular, strategic, or reflexive questions? Family Process, 27, 1-15.

Vidgen, A., \& Williams, R. (2001). Letter-writing practices in a child and family service. Journal of Family Therapy, 2, 317-326.

White, M., \& Epston, D. (1990). Médios narrativos para fines terapêuticos. Barcelona: Paidós.

\section{Nota:}

1 Gergen (1996) propõe uma teoria do processo de significação na qual estabelece que o sentido depende de uma ação suplementar, ou seja, de que um ato tem seu sentido a partir da ação do outro. Assim, evita-se o entendimento que a palavra ou o ato em si possuem sentido, independentes do contexto social e histórico no qual se apresentam. 